\title{
The 2010 NICE COPD Guidelines: how do they compare with the GOLD guidelines?
}

\author{
${ }^{*}$ Kevin Gruffydd-Jones ${ }^{\mathrm{a}}$, Chris Loveridge ${ }^{\mathrm{b}}$ \\ a General Practitioner, Box Surgery, Box, Wiltshire, UK; Member of the NICE COPD Guidelines Development Group \\ ${ }^{\mathrm{b}}$ Specialist Nurse, Education For Health, Warwick, UK; Member of the NICE COPD Guidelines Development Group
}

Original submitted 5th July 2010; resubmitted 3rd October 2010; revised 21st November 2010; accepted 22nd December 2010; online 24th March 2011

\begin{abstract}
The UK National Institute for Health and Clinical Excellence (NICE) has produced a 2010 partial update of its original 2004 Guidelines on COPD management. The definition of airflow obstruction has been altered to a post-bronchodilator $\mathrm{FEV} / \mathrm{FVC}$ ratio $<0.7$ and the severity of airflow obstruction has been similarly aligned with the Global initiative for Obstructive Lung Disease (GOLD) guideline definition. However, patients with GOLD Stage 1 (i.e. FEV 1 predicted $\geq 80 \%$ ) must be symptomatic for a diagnosis of COPD to be made under the new NICE criteria. Recent large scale trials have resulted in a new inhaled pharmacotherapy algorithm which includes early use of inhaled corticosteroid/long-acting $\beta_{2}$-agonist combination therapy for patients with an FEV $1<50 \%$ predicted. In spite of an apparent emphasis on pharmacotherapy, both GOLD and NICE Guidelines emphasise that COPD is a multi-system disease requiring a multidimensional approach to treatment. In particular, the importance of smoking cessation and pulmonary rehabilitation is reiterated, the latter not only being of use in managing stable disease but also following hospital discharge.

(c) 2011 Primary Care Respiratory Society UK. All rights reserved.

K Gruffydd-Jones and C Loveridge. Prim Care Respir J 2011; 20(2): 199-204

doi: 10.4104/pcrj.2011.00011
\end{abstract}

Keywords COPD, primary care, GOLD, NICE, guidelines, management, diagnosis, pharmacotherapy.

\section{Introduction}

Chronic obstructive pulmonary disease (COPD) continues to exert a heavy burden on the individual health of patients and also on health economies throughout the world. It is estimated that COPD will be the third leading cause of death worldwide by the year $2020 .^{\prime}$

There is increasing recognition that COPD is not just a disease of the lungs, but has systemic effects requiring a multidimensional assessment and an holistic approach to management. There have also been recent large scale clinical trials looking at the effects of pharmacotherapy in reducing future risk of exacerbations, disease progression and mortality. ${ }^{2-5}$ The emergence of this new evidence prompted a 2010 update of the UK National Institute for Clinical Excellence (NICE) Guidelines for $\mathrm{COPD}^{6}$ and also informed development of the 2009 update of the Global Initiative for Chronic Obstructive Lung Disease (GOLD) Guidelines.'

This article discusses the principal changes in the 2010 NICE
Guidelines from a primary care perspective, and compares these to the recommendations in the 2009 GOLD Guidelines.

\section{Methodology}

Both the 2010 NICE Guidelines ${ }^{6}$ and the 2009 GOLD Guidelines' are partial updates of previous Guidelines from $2004^{7}$ and $2007^{8}$, respectively. Only a limited number of areas of COPD management were chosen for the 2010 NICE update on the basis that there had been significant new evidence which might change the original recommendations. The update ${ }^{6}$ focuses on diagnosis, assessment of severity, and some aspects of management of stable disease. Other areas such as management of acute exacerbations and oxygen therapy were not updated.

The original $\mathrm{NICE}^{7}$ and $\mathrm{GOLD}^{8}$ Guideline recommendations were based on the traditional method of grading evidence on a hierarchal basis; for example, the NICE 2004 Guideline used criteria ranging from Grade 1 (meta-

\footnotetext{
* Corresponding author: Dr. Kevin Gruffydd-Jones, Box Surgery, London Road, SN13 8QS, UK

Tel: +44 (0)1225 744195 E-Mail: gruffbox@btinternet.com
} 
analysis, systematic reviews of randomised controlled trials) to Grade IV (Expert opinion). The new evidence examined by NICE was assessed by the GRADE method of analysis ${ }^{9}$ which rates the quality of evidence (irrespective of study type) from "high" to "low" on factors such as "inconsistency of results" and "limitations of study design". In addition, NICE has assessed cost-effectiveness of interventions using economic modeling.

\section{Diagnosis of COPD}

A diagnosis of COPD is made on the basis of the presence of characteristic symptoms (e.g. cough, sputum production and breathlessness), clinical signs, and the demonstration of airflow obstruction on spirometry.

The 2004 NICE Guidelines did not state whether pre- or post-bronchodilator spirometric values should be used to demonstrate airflow obstruction. However, the new Guidelines recommend use of the post-bronchodilator $\mathrm{FEV}_{1} / \mathrm{FVC}$ ratio, which has a greater likelihood of discriminating groups at high and low risk of COPD than pre-bronchodilator values. This recommendation ${ }^{6}$ is in line with international guidelines ${ }^{1}$ and the UK Quality and Outcomes Framework (QOF) for General Practice. ${ }^{10}$ Similarly the post-bronchodilator $\mathrm{FEV}_{1}$ value is used to assess severity of airflow obstruction.

The actual dosage of $\beta_{2}$-agonist needed for bronchodilation is not stated in the NICE Guidelines, but administration of four separate puffs of $100 \mathrm{mcg}$ salbutamol via metered-dose inhaler (MDI) and spacer has been recommended in standards published for primary care spirometry" and this is widely accepted practice.

There has been considerable controversy as to whether the diagnosis of obstructive lung disease should be based on a fixed $F E V_{1} / F V C$ ratio of less than 0.7 , or whether it should be based on an $\mathrm{FEV}_{1} / \mathrm{FVC}$ ratio below the lower limit of normal (LLN) i.e. the bottom $5 \%$ of a healthy population. The reason for this is that the fixed ratio may overdiagnose airflow obstruction in older people and underdiagnose airflow obstruction in younger people. In spite of increasing recognition of these limitations, there is conflicting evidence on the superiority of LLN versus the fixed 0.7 ratio in predicting a diagnosis of COPD, ${ }^{6}$ and there is a paucity of up-to-date postbronchodilator reference values for the LLN. For these reasons both NICE and GOLD continue to recommend the use of the fixed 0.7 ratio. However, one needs to consider alternative diagnoses in:

a) older patients with an $\mathrm{FEV}_{1} / \mathrm{FVC}$ ratio $<0.7$ but without typical symptoms of COPD, and

b) younger patients with typical symptoms of COPD but an $\mathrm{FEV}_{1} / \mathrm{FVC}$ ratio $>0.7$.

Further discussion of this topic and advice for carrying out spirometry in primary care can be found in the Standards for Diagnostic Spirometry in Primary Care published in this journal in 2009. ${ }^{11}$

\section{Assessment of severity of disease}

Traditionally, disease severity has been equated with the degree of airflow obstruction. The current GOLD Guidelines continue to use a spirometric classification of disease severity based on the $\%$ predicted FEV, value. However, in recent years there has been an increasing recognition that COPD is not just a disease of the lungs but has systemic manifestations such as depression, muscle wasting and general fatigue. Therefore, both the $2004^{7}$ and $2010^{6}$ NICE Guidelines emphasise that an assessment of disease severity should be based not just on the degree of airflow obstruction but on a multidimensional assessment based on other factors such as disability and exacerbation frequency. Nevertheless, the degree of airflow obstruction is still an important part of severity assessment. The severity grading in the 2004 NICE Guidelines? was out of line with international guidelines, and this has largely been rectified in the 2010 update $^{6}$ (see Table 1)

One important difference between NICE and GOLD remains. The 2004 NICE Guidelines excluded GOLD Stage 1 patients (i.e. those with an $\mathrm{FEV}_{1} / \mathrm{FVC}$ ratio $<0.7$ but an $\mathrm{FEV}_{1} \geq 80 \%$ ) from

Table 1. Degree of severity of airflow obstruction according to NICE and GOLD Guidelines.

Severity of airflow obstruction

\begin{tabular}{|c|c|c|c|c|}
\hline $\begin{array}{l}\text { Post-Bronchodilator } \\
\text { FEV }_{1} / \text { FVC }\end{array}$ & $\begin{array}{l}\mathrm{FEV}_{1} \% \\
\text { Predicted }\end{array}$ & NICE 2004 & GOLD 2009 & NICE 2010 \\
\hline & & & Post-Bronchodilator & Post-Bronchodilator \\
\hline$<0.7$ & $50-79 \%$ & Mild & Stage 2 Moderate & Moderate \\
\hline$<0.7$ & $30-49 \%$ & Moderate & Stage 3 -Severe & Severe \\
\hline
\end{tabular}


having a diagnosis of COPD. The harmonisation of the NICE severity grading with GOLD could potentially increase very considerably the number of patients diagnosed with the disease. However, there is little evidence that asymptomatic patients fulfilling the GOLD Stage 1 criteria have an increased risk of deterioration in health status or $\mathrm{FEV}_{1}$. Therefore, NICE have recommended that a diagnosis of COPD in patients with mild airflow limitation ( $\mathrm{FEV}_{1} / \mathrm{FVC}<0.7 ; \mathrm{FEV}_{1}>80 \%$ predicted) should only be made in the presence of symptoms.

The recognition that assessment of COPD disease severity requires a multi-dimensional approach has led to the development of multi-dimensional indices. The BODE index ${ }^{12}$ assesses disease severity by measuring Body Mass Index (BMI), the degree of airflow Obstruction (FEV $1 \%$ predicted), Dyspnoea (MRC Dyspnoea score), and Exercise limitation (6-minute walking test), and is seen as a an evidence-based prognostic indicator. The 2010 NICE Guidelines conclude that this multidimensional assessment tool is a better predictor of mortality and exacerbation rate than $\mathrm{FEV}_{1}$ alone. ${ }^{6}$ Unfortunately, the 6-minute walking test is not very practical to perform in primary care, and so other more primary care-friendly tools have been developed such as the Dyspnoea, airways Obstruction, Smoking status, and Exacerbation frequency (DOSE) index, ${ }^{13}$ the COPD Control Questionnaire (CCQ), ${ }^{14}$ and the COPD Assessment Tool (CAT). ${ }^{15}$ However, these assessment tools have not yet been formally assessed by GOLD or NICE.

\section{Management of COPD: inhaled pharmacotherapy}

One of the major changes in the 2010 NICE Guidelines is the recommendation regarding inhaled pharmacotherapy. Publication of major studies such as TORCH ${ }^{2}$ and UPLIFT $^{5}$ has refocused attention away from simply treating current symptoms and improving quality of life ("current control") to focusing on preventing future exacerbations, reducing mortality, and preventing disease progression (prevention of "future risk"). Clinical and economic evaluation of studies comparing various inhaled pharmacotherapy modalities has resulted in the treatment algorithm shown in Figure 1.

The treatment choice following initial short-acting $\beta_{2}-$ agonist (SABA) or antimuscarinic agent (SAMA) bronchodilation for persistent breathlessness or exacerbations is determined by the level of post bronchodilator FEV 1 . If the $\mathrm{FEV}_{1}$ is $\geq 50 \%$, then the recommendation is to use a longacting antimuscarinic agent (LAMA) such as tiotropium, or a long-acting $\beta_{2}$-agonist (LABA) such as salmeterol or formoterol. If the $\mathrm{FEV}_{1}$ is $<50 \%$ then the initial choice is between a LAMA or LABA/inhaled corticosteroid (ICS) combination. If ICS therapy is declined or not tolerated then treatment with a LAMA plus a LABA should be considered. In the presence of persistent symptoms or exacerbations, then triple therapy with ICS/LABA and LAMA is recommended.

Where there is a choice of therapy, the Guidelines do not

\section{Figure 1. Algorithm for inhaled pharmacotherapy (from the NICE Guidelines 2010' reproduced with permission).}

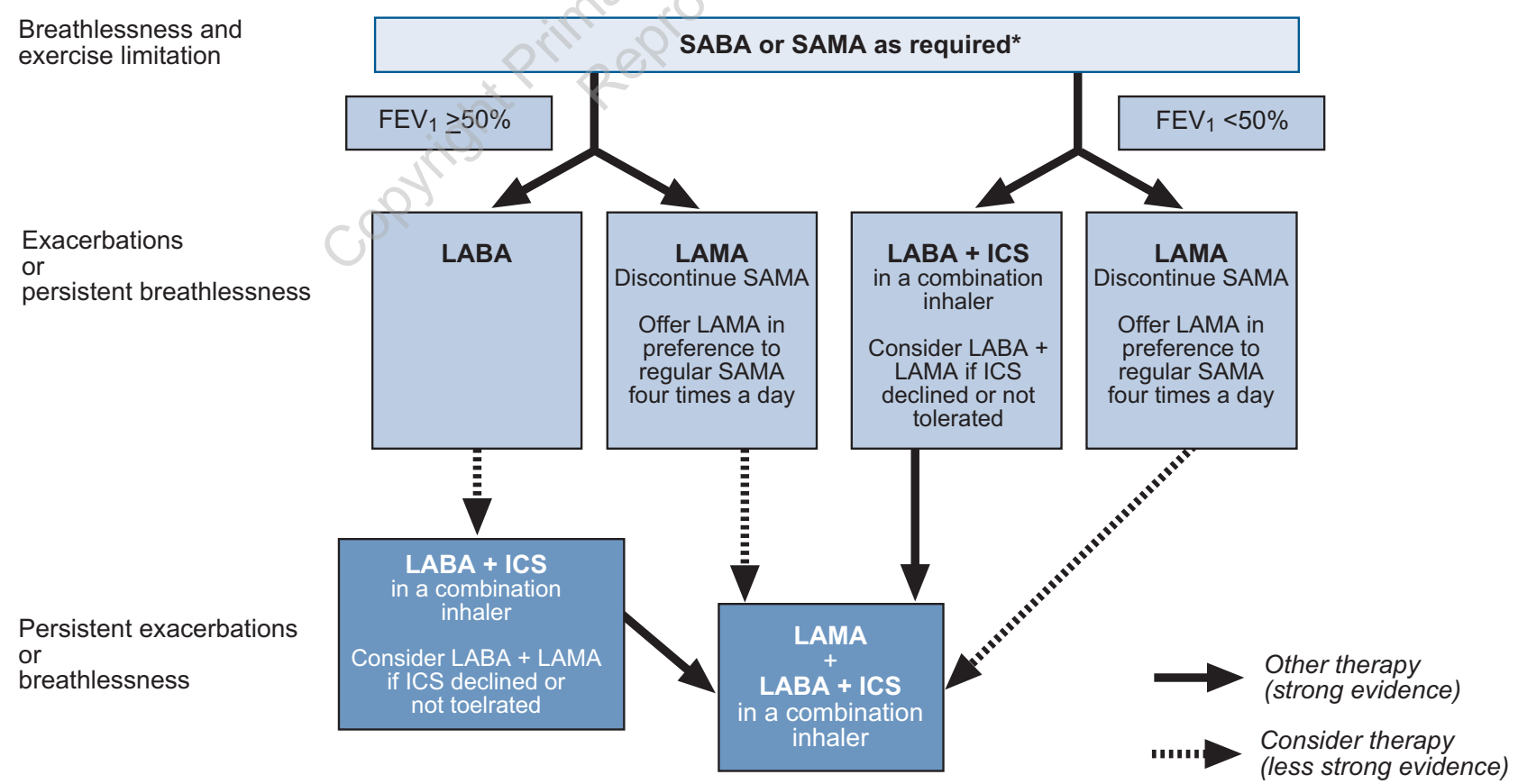

SABA: short-acting $\beta_{2}$-agonist; SAMA: short-acting muscarinic antagonist; LABA: long-acting $\beta_{2}$-agonist; LAMA: long-acting muscarinic antagonist; ICS: inhaled corticosteroid *SABA (as required) may continue at all stages 
recommend which specific drug should be used but state that this choice should be based on cost, inhaler technique and patient preference. In the UK there has been some pressure by primary care pharmaceutical advisers on general practitioners (GPs) to prescribe regular four times-daily ipratropium in preference to the more expensive once-daily LAMA tiotropium. The evidence shows that tiotropium is not only more clinically effective but is also more cost effective than four times-daily ipratropium. ${ }^{1}$

It is important to note that NICE recommends the use of ICS/LABA combination and not the use of ICS alone. Not only is ICS monotherapy unlicensed for the treatment of COPD in the UK, but the evidence for the use of these agents lies primarily with the ICS/LABA combination inhalers. ${ }^{6}$

Evidence regarding a potentially increased risk of pneumonia with ICS was assessed by NICE; it concluded that there was a small increased risk of non-fatal pneumonia with ICS usage and that patients should be warned about this. Reassuringly, there appears to be no increased risk of cataract or osteoporosis with ICS use - the latter appearing to be linked to disease severity rather than to drug use.

In contrast to NICE, the GOLD Guidelines (see Figure 2) advocate the initial usage of bronchodilator therapy for symptomatic disease with ICS added in for patients with an
$\mathrm{FEV}_{1}<50 \%$ and repeated exacerbations (for example, three exacerbations in the last three years).

As a result of these changes to the NICE Guidelines, ${ }^{6}$ not only will the decision to continue a therapy be based on the patient's symptomatic response (or improvement in lung function/health status) but also in the drug's potential to reduce further risk. This might be made easier by the availability of an assessment tool in primary care which not only reflects future risk but is also sensitive to change caused by treatment.

Another important implication of the updated GOLD and NICE guidance is that spirometry needs to be included in the routine COPD review, since the degree of airflow limitation is an important guide to pharmacotherapy (as per Figure 1). This reliance on the \% predicted $\mathrm{FEV}_{1}$ to guide pharmacotherapy is at odds with the general thrust of the NICE guidelines towards multidimensional assessment - but is due to the fact that the entry criteria for many of the major trials was based on lung function. There is an urgent need to develop multidimensional assessment measures of severity which can be used to inform entry into therapeutic COPD trials.

In spite of the prominence of pharmacotherapy in the 2010 NICE update, ${ }^{6}$ the Guidelines continue to emphasise the role of non-pharmacological therapy such as smoking cessation, oxygen treatment, and lifestyle changes. In particular, the beneficial role

Figure 2. Pharmacotherapy algorithm from GOLD Guidelines 2009'. Content from GOLD Executive Summary used with permission from the Global Initiative for Chronic Obstructive Lung Disease (GOLD), www.goldcopd.org.

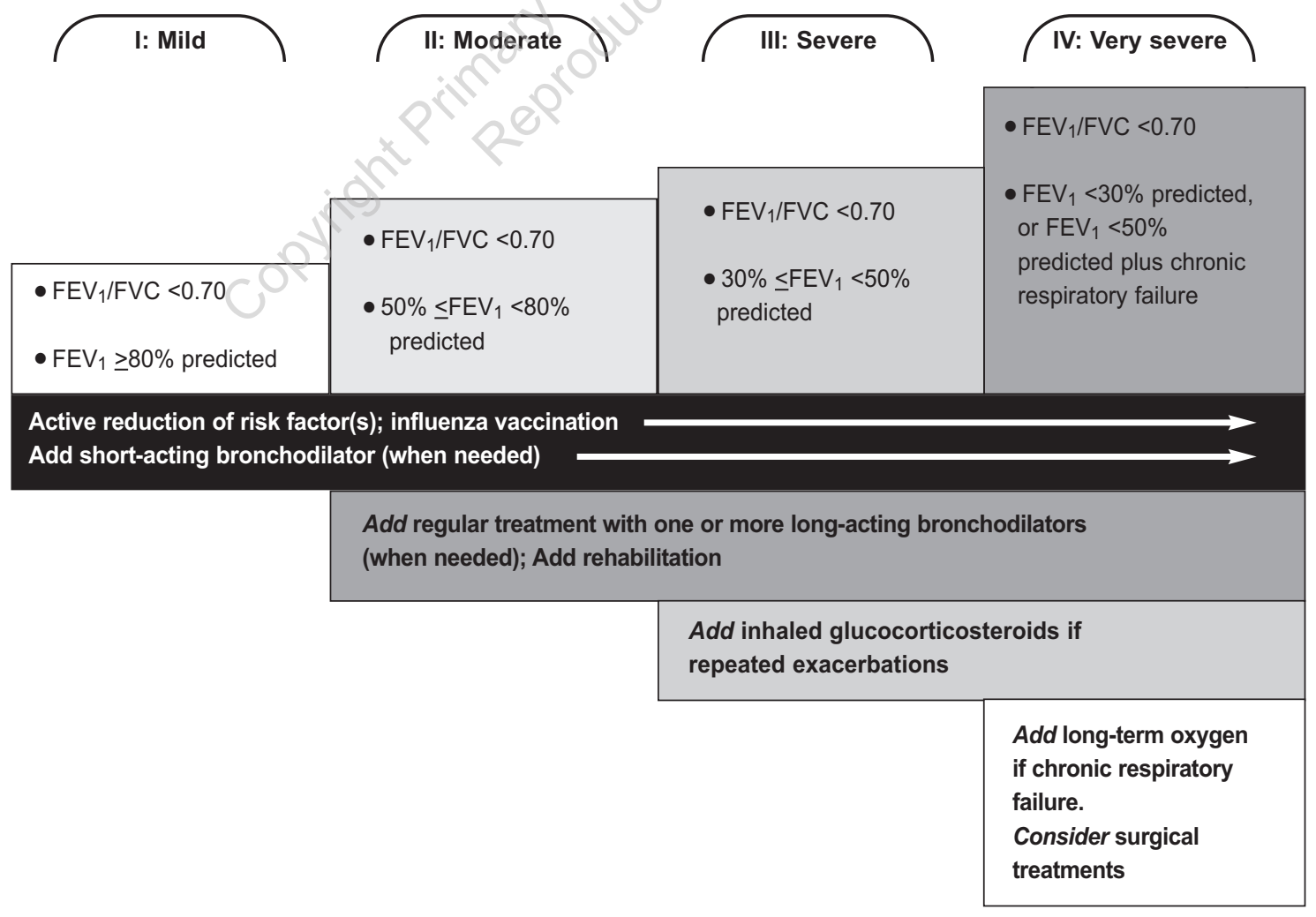


Figure 3. Patient-centred management of COPD in Primary Care. (From Reference 16, PCRS-UK "Diagnosis and Management of COPD in Primary Care").

\begin{tabular}{|c|c|c|c|c|}
\hline \multicolumn{3}{|c|}{$\begin{array}{l}\text { ALL PATIENTS } \\
\text { Smoking cessation advice } \\
\text { Patient education / self management } \\
\text { Assess co-morbidity } \\
\text { ASSESS BMI: Dietary Advice if BMI > } 25\end{array}$} & \multicolumn{2}{|c|}{$\begin{array}{l}\text { Exercise promotion } \\
\text { Pneumococcal vaccination } \\
\text { Annual influenza vaccination } \\
\text { Specialist dietary referral if } \mathrm{BMI}<20\end{array}$} \\
\hline $\begin{array}{c}\text { SYMPTOMS? } \\
\text { Breathlessness } \\
\text { Short-acting } \\
\text { bronchodilators } \\
\text { ( } \beta \text {-agonist/antimuscarinic) } \\
\text { for relief of symptoms }\end{array}$ & $\begin{array}{c}\text { FUNCTIONAL } \\
\text { LIMITATION? } \\
\text { MRC score } \geq 3 \\
\text { Optimise } \\
\begin{array}{c}\text { pharmacotherapy } \\
\text { (See algorithm) }\end{array} \\
\begin{array}{c}\text { Offer pulmonary } \\
\text { rehabilitation }\end{array} \\
\text { Screen for } \\
\text { anxiety/depression }\end{array}$ & $\begin{array}{c}\text { EXACERBATIONS } \\
\text { (Oral steroids/ } \\
\text { antibiotics/ } \\
\text { hospital } \\
\text { admissions) } \\
\text { Optimise } \\
\text { pharmacologic } \\
\text { therapy } \\
\text { Discuss action plans } \\
\text { including use of standby } \\
\text { oral steroids and } \\
\text { antibiotics }\end{array}$ & 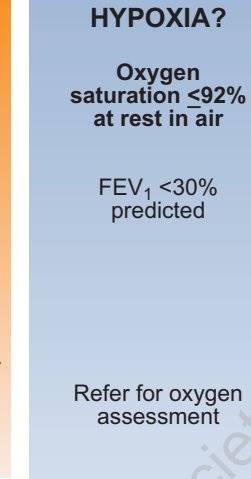 & 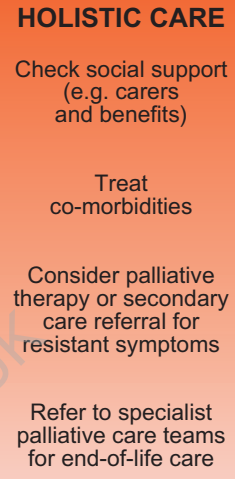 \\
\hline
\end{tabular}

of pulmonary rehabilitation is restated; new evidence shows that following hospital admission, early pulmonary rehabilitation (within one month of admission) can reduce the rate of further exacerbations and readmission. This reinforces the importance of post-hospital discharge review in order to optimise pharmacological and non-pharmacological treatments.

The move towards a multisystem, holistic approach to COPD management has been summarised in a treatment algorithm (see Figure 3) produced by the Primary Care Respiratory Society-UK and explained further in their publication "The Diagnosis and Management of Chronic Obstructive Pulmonary Disease in Primary Care". ${ }^{16}$

\section{Conclusions}

Changes to the spirometric criteria for diagnosing airflow obstruction in the 2010 partial update of the NICE Guideline largely mirror the GOLD criteria. The GOLD Guidelines assess disease severity on the basis of the degree of airflow obstruction, whereas the NICE Guidelines place increasing emphasis on multi-dimensional assessment. Inhaled bronchodilators are the cornerstone of pharmacotherapy in both sets of Guidelines, with combined ICS/LABA inhalers being reserved for more severe disease. Smoking cessation and pulmonary rehabilitation remain key interventions, with NICE recommending pulmonary rehabilitation post hospital discharge after an acute exacerbation of COPD.

\section{Acknowledgement}

The authors wish to thank Erica Haines for her helpful comments concerning this document.

\section{Key points}

- A diagnosis of COPD should be made in the presence of characteristic signs and symptoms, and obstructive spirometry is characterised by a post-bronchodilator $\mathrm{FEV}_{1} / \mathrm{FVC}$ ratio of $<0.7$

- In patients with an $\mathrm{FEV}_{1} / \mathrm{FVC}$ ratio $<0.7$ and $\mathrm{FEV}_{1} \%$ predicted $\geq 80 \%$, COPD should only be diagnosed in the presence of symptoms

- A multi-dimensional assessment tool (BODE) is better at determining disease severity than the degree of airway obstruction alone

- The initial choice of regular pharmacotherapy for persistent symptoms when the $\mathrm{FEV}_{1} \%$ predicted is $\geq 50 \%$ is either a longacting $\beta_{2}$-agonist (LABA) or a long-acting antimuscarinic agent (LAMA). Where the $\mathrm{FEV}_{1} \%$ predicted is $<50 \%$, the choice is between a LAMA or inhaled corticosteroid (ICS)/LABA combination

- COPD is a multisystem disease and should be treated using a multi-dimensional patient-centred approach

\section{Conflicts of interest}

KGJ has acted as a consultant for and spoken at meetings sponsored by AstraZeneca, GlaxoSmithKline, Novartis, Napp, Merck Sharp \& Dohme, Boehringer Ingelheim and Chiesi.

$\mathrm{CL}$ has spoken at meetings sponsored by GlaxoSmithKline, AstraZeneca and Boehringer Ingelheim/Pfizer.

\section{References}

1. Global Strategy for the Diagnosis, Management and prevention of Chronic Obstructive Pulmonary Disease 2009. Global Initiative for Chronic obstructive Lung Disease (GOLD) www.goldcopd.com 
2. Calverley PM, Anderson JA, Celli B, et al. Salmeterol and fluticasone propionate and survival in chronic obstructive pulmonary disease. $N$ Engl J Med 2007;356(8):775-89. http://dx.doi.org/10.1056/NEJMoa063070

3. Calverley P, Pauwels R, Vestbo J, et al. Combined salmeterol and fluticasone in the treatment of chronic obstructive pulmonary disease: a randomised controlled trial. Lancet 2003;361(9356):449-56. http://dx.doi.org/ 10.1016/S0140-6736(03)12459-2

4. Szafranski W, Cukier A, Ramirez A, et al. Efficacy and safety of budesonide/ formoterol in the management of chronic obstructive pulmonary disease. Eur Respir J 2003;21(1):74-81. http://dx.doi.org/10.1183/09031936.03.00031402

5. Tashkin DP, Celli B, Senn S, Burkhart D, Kesten S, Menjoge S, Decramer M; UPLIFT Study Investigators. A 4 year trial of Tiotropium in chronic obstructive pulmonary disease. New Eng J Med 2008;359(15):1543-54. http://dx.doi.org/10.1056/NEJMoa0805800

6. National Clinical Guideline Centre. (2010) Chronic obstructive pulmonary disease: management of chronic obstructive pulmonary disease in adults in primary and secondary care. London: National Clinical Guideline Centre.

7. Pearson M. Chronic obstructive Pulmonary Disease. National clinical guideline on management of chronic obstructive pulmonary disease in adults in primary and secondary care. Thorax 2004;59(Suppl 1):1-232

8. Global Strategy for the Diagnosis, Management and prevention of Chronic Obstructive Pulmonary Disease 2007. Global Initiative for Chronic Obstructive Lung Disease (GOLD) www.goldcopd.com

9. Guyatt $\mathrm{GH}$, Oxman $A D$, Vist $\mathrm{GE}$, et al. GRADE - an emerging consensus on quality of evidence on strength of recommendations. BMJ 2008;336:924-6. http://dx.doi.org/10.1136/bmj.39489.470347.AD

10. The Quality and Outcomes Framework (QOF) www.ic.nhs.uk

11. Levy ML, Quanjer PH, Booker R, Cooper BG, Holmes S, Small, IR. Diagnostic Spirometry in Primary Care. Proposed Standards for general practice compliant with American Thoracic Society and European Respiratory Society recommendations. Prim Care Respir J 2009;18(3):130-47. http://dx.doi.org/10.4104/pcrj.2009.00054

12. Celli BR, Cote CG, Marin JM, et al. The Body-Mass Index, Airflow Obstruction, Dyspnea, and Exercise Capacity Index in Chronic Obstructive Pulmonary Disease. NEJM 2004;350:1005-12. http://dx.doi.org/10.1056/NEJMoa021322

13. Jones RC, Donaldson GC, Chavannes $\mathrm{NH}$, et al. Derivation and validation of a composite index of severity in chronic obstructive pulmonary disease: the DOSE Index. Am J Respir Crit Care Med 2009;180:1189-95. http://dx.doi.org/10.1164/rccm.200902-02710C

14. Van der Molen T, Willemse BW, Schokker S, ten Hacken NH, Postma DS, Juniper EF. Development, validity and responsiveness of the Clinical COPD Questionnaire. Health Qual Life Outcomes 2003;1:13. http://dx.doi.org/10.1186/1477-7525-1-13

15. Jones PW, Harding G, Berry $P$, et al. The COPD Assessment Tool (CAT) www.catestonline.org. Development and first validation of the COPD Assessment Test. Eur Respir J 2009;34(3):648-54.

16. Diagnosis and Management of COPD in Primary Care. Primary Care Respiratory Society (UK) 2010 www. pcrs-uk.org

\section{Available online at http://www.thepcrj.org}

